\begin{tabular}{r|r}
$n$ \\
\hline
\end{tabular}

Rev. Latinoam. Psicop. Fund. III, 3, 115-123

\title{
Uma perspectiva existencial do tempo*
}

\author{
Erwin W. Straus
}

"Porque toda a carne é como a erva e toda a grandeza do homem é como a flor da erva. A erva murcha e sua flor seca.” A Bíblia, a poesia e os mitos, as peças de teatro e os contos apresentam uma vasta documentação de como o homem experimentou de perto os aspectos existenciais do tempo, desde que foi expulso do paraíso. Isso não surpreende, uma vez que nascimento e morte, crescimento e decadência são tão evidentes como o dia e a noite, o verão e o inverno. Muito antes de os equinócios serem descobertos, muito antes da idéia de se dividir em partes iguais o todo de um dia, sabia-se que existia um tempo para o trabalho, um tempo para a oração, dias de trabalho e dias de repouso, horas felizes e horas de desgraça, e assim por diante. Alguém poderia se surpreender pelo fato de tão poucas tentativas terem sido feitas, no sentido de bem delinear esse assunto, através de uma pesquisa conceitual. Existem, no entanto, boas razões para isso: o tempo existencial não pode ser separado da vida e da história de cada indivíduo; a relação presente-pas-

* Este texto foi traduzido da versão inglesa "An existential approach do time”, in Annals New York Academy of Sciences, v. 138, n 2, pp. 759-766, 1967. Ele está também publicado em alemão, como “Zeit in existentieller Sicht”, in Jahrbuch für Psychologie, Psychotherapie und medizinische Anthropologie, 16 (1,2 - 1,8), 1968. Para a presente tradução, servimo-nos ainda de uma longínqua mas inestimável ajuda de Werner Streitwieser, que se prestou a traduzir, oralmente e em primeira leitura, o texto alemão.

Tradução de José Newton Garcia de Araújo, professor da UFMG e da PUC-Minas. 
sado-futuro não pode ser reduzida ao esquema mais cedo - mais tarde; o tempo da existência é finito; eventos situados entre um começo e um fim têm apenas um valor de posição - um ano na juventude e um ano na velhice não são comensuráveis; o tempo da existência não pode ser quantificado.

Não foi a filosofia contemporânea que descobriu o tempo existencial, apenas sua interpretação é nova, especialmente aquela apresentada por Heidegger, em Ser e tempo, em que este autor dá ênfase a temas como possibilidade, finitude (morte) e Nada. Mas a Analítica do Dasein não é um estudo antropológico. É um método de interpretação a serviço de interesses ontológicos. A diferença ôntico-ontológica deve pois ser respeitada. Cuidado, culpa, apelo da consciência, estrutura "ex-stática" do tempo, até mesmo a distinção autêntico-inautêntico devem ser apropriadamente entendidos. Inautenticidade é um modo de ser do Dasein; é um termo ontológico, não psicopatológico, não designa um comportamento neurótico.

Uma vez que os aspectos experienciais do tempo constituem o tema especial desta exposição, vou abordar o tempo existencial a partir de um horizonte ôntico. Começo com uma experiência clínica, na qual um comportamento mórbido isola e amplia certos aspectos, como em um experimento.

Bertha L., uma paciente observada anos atrás por von Gebsattel, é um caso típico. O relato dessa jovem em nada perdeu de sua atualidade, já que ela tinha um admirável dom para se expressar e descrever suas angústias cronofóbicas. Em uma de suas entrevistas gravadas, Bertha assim fala:

Durante todo o dia eu tenho um sentimento de angústia, relacionado com o tempo. Eu nunca paro de pensar que o tempo se esvai, que ele passa. Agora mesmo, enquanto estou falando com você, fico pensando a respeito de cada palavra: passou, passou, passou... Isso começa logo que eu acordo e está muitas vezes ligado a ruídos. Quando ouço o trinar de um pássaro, penso: isso demorou um segundo. Gotas d'água são insuportáveis e me deixam furiosa, pois eu sempre tenho que pensar: agora passou um segundo e de novo um outro segundo. Isso também acontece quando ouço o tic-tac do relógio. Eu tive que parar de dar corda nos meus relógios e os escondi... Não consigo viajar de trem, porque a idéia de que tenho de estar na estação a tal hora exata me é insuportável... Quando minha irmã escreve que virá no próximo domingo, às oito horas e nove minutos, isso me causa um sentimento estranho. Não consigo entender como as pessoas podem fazer planos, anunciar com antecedência suas ações futuras e, ainda assim, permanecer completamente tranqüilas... Quero dizer, intelectualmente posso acompanhar o que elas dizem, mas fico realmente perplexa de como elas conseguem falar de forma tão simples e tranqüila, sem estar constantemente pensando: agora eu estou falando isso, isso dura tanto tempo, depois vou fazer aquilo e depois aquilo outro; tudo isso vai durar sessenta anos, então eu vou morrer, depois virão outros que também viverão mais ou menos tanto quanto eu, vão comer e dormir como eu, e depois ainda virão outros, e assim por diante, sem nenhum sentido, durante milhares de anos. 
Berta falou como se estivesse citando o Eclesiastes: “Tudo é vaidade. Que proveito tira o homem de todo o trabalho com que ele se afadiga debaixo do sol? Uma geração passa, outra vem” (I: 2-4). ${ }^{1}$ Porém há uma grande diferença entre o desespero dela [Berta] e a resignação dele [o Eclesiastes]. Ela está sendo tragada pelo Maelstrom do tempo, enquanto o Pregador medita à sua margem. E porque tudo desaparece, o conselho dele é: "não há nada melhor para o homem que comer, beber e desfrutar do produto de seu trabalho" (2: 24). Bertha não tinha uma disposição afetiva para aceitar tal conselho. Com efeito, suas queixas eram dominadas por dois temas: em seu agoniado sofrimento, ela experimentava a finitude de sua própria existência, juntamente com o ininterrupto passar do tempo. Algumas vezes, ela se sentia como se tivesse descoberto um parentesco entre a ordem vivida e experienciada de seu devir pessoal e alguns aspectos universais do tempo do mundo:

Muitas vezes penso que não estou doente, mas que descobri alguma coisa que permanece oculta para as outras pessoas; que formei para mim uma visão de mundo tão infeliz que nem pode ser partilhada com os outros, mas que é uma visão bastante lógica; na verdade, não entendo como as outras pessoas podem pensar de outra maneira. Esse jeito de pensar é terrível, é como algo mortal, ligado à idéia de suicídio - sempre que faço alguma coisa, a distância que me separa da morte vai ficando mais curta - concretamente, não tenho medo da morte, eu até a imagino bonita, mas o pensamento de que tudo passa e que a vida está constantemente se encurtando, isso me horroriza... Quando estou fazendo crochê, não me entusiasmo ao ver a peça de lã crescer, apenas fico pensando que, junto com o crescimento da peça, o espaço de minha vida vai ficando mais e mais encolhido. Essa situação é intolerável. Por isso, para me livrar dessas idéias, vou pôr fim à minha vida, embora a vida seja preciosa para mim.

Bertha não sabia que, com sua observação sobre o tecer, ela estava parafraseando o conto de Balzac La peau de chagrin (O chagrém mágico). ${ }^{2}$

Estamos inclinados a admitir que a visão de mundo de Berta é uma espécie de sub-tema subordinado ao tema principal: a ameaça paralisadora, ante a aproximação constante da morte. Bertha relata que o aparecimento desse seu problema

1. A palavra "vaidade” se refere a “desvanecer” e ambas se referem a "vão”, no sentido de "vazio”. A palavra hebraica original - literalmente a respiração [ou expiração] - tem uma forte conotação temporal; portanto, é bastante significativo que o verso "uma geração passa, outra

2. Esse conto mostra como o dono de uma pele mágica, que garante a realização dos desejos, está condenado a ver essa pele murchando um pouco, cada vez que um de seus desejos é realizado. Cada “encolhimento” da pele o traz para mais perto da morte. Ver a nota introdutória de Allen Hodge à tradução de Paul Cedar. 
aconteceu tão de repente como um raio. "Isso aconteceu quando o movimento das pernas de um ciclista me chamou a atenção subitamente. Então, pela primeira vez, fiquei dominada pela idéia 'pra cima, para baixo, um segundo, mais um segundo'”. Seja qual for a ordem de relação entre esses dois temas, a dolorosa fascinação de Bertha pelo passar do tempo não advinha de um trabalho de reflexão. Ela era análoga a uma percepção sensorial imediata, o que é indicado pela freqüente ocorrência de ruídos.

O aspecto aniquilador do tempo que domina a experiência de Berta não é uma invenção mórbida. ${ }^{3}$ Sua doença é uma espécie de cegueira prospectiva, um obstáculo para o crescimento, para que coisas novas apareçam e para uma inesgotável gama de possibilidades. Com sua "escolha negativa”, Bertha representa um problema para a psiquiatria, mas sua alternativa básica requer e permite ainda outras elucidações.

As Parcas, na mitologia grega, fiavam os fios [da vida]. Cloto começava a fiar, Láquesis continuava, até que Átropos cortava cada fio. Aí há um começo e um fim, mas não um começo e um fim do tempo. O tempo, tal como nós o entendemos, não começa nem termina. Mas o tempo da vida começa e termina. Na medida em que ele se estende entre dois termos, tudo o que acontece, acontece mais cedo ou mais tarde, no decorrer da vida. Cada acontecimento tem sua posição única e sua fisionomia própria, determinada por sua relação com o nascimento e a morte, com o passado e com o futuro, com a realidade e com a possibilidade. Mesmo que início e fim estejam colocados em lugares opostos, as duas posições - o terminus a quo e o terminus ad quem - não são termos simétricos. O início é um dado, um fato estabelecido. Mas o fim, apesar de certo, é imprevisível. A morte é uma possibilidade não datada, embora já presente: "se ela for agora, ela não é 'por-vir' [futura]; se não é 'por-vir', ela será agora; se não for agora, ela ainda chegará”.

Para a tarefa de medição do tempo, o começo e o fim de um acontecimento devem ser considerados como dois termos simétricos. Assim sendo, a duração somente pode ser estabelecida numa visada retrospectiva. Portanto, a medição restringe o tempo à ordem do um após o outro, e por isso, inevitavelmente, exclui a observação do fluxo contínuo do tempo, com seu tríplice aspecto temporal - o presente, o passado e o futuro. ${ }^{4}$ Assim, por exemplo, no horário do relógio, a rela-

3. A interpretação de Ser e nada é um dos temas centrais de O ser e o tempo de Heidegger. SCM Press: London, 1962. Ver a concisa apresentação de M. Wyschogrod's.

4. Quando medimos o tempo, duas séries de eventos devem ser coordenadas, de tal forma que o início e o fim de uma série (por exemplo, de uma reação biológica ou de uma corrida de carros) determine o início e o fim da uma outra (por exemplo, um cronômetro ou algum outro instru- 
ção mais cedo-mais tarde pode ser estabelecida entre dois pontos quaisquer do mostrador. Mas essa relação vai caminhando com os ponteiros sobre o mostrador. Enquanto 7:45h é mais cedo do que 8:00h, 8:00h é mais cedo do que 8:30h. As qualificações “cedo" e "tarde”, no entanto, não são, em seu conteúdo, relativas uma à outra. Elas se referem ao começo ou ao fim do dia, do ano, da vida ou da existência. Cedo e tarde, assim como jovem ou velho, designam fases, no desenrolar do devir individual.

O fato de que 8:00h ocorrem antes de 8:15h e 8:15h antes de 8:30h caracteriza o tempo fluindo de maneira uniforme, indiferente a todos os acontecimentos. Mas o tempo da vida, que se estende da concepção até a morte, não é de modo algum homogêneo. Situados entre o primeiro choro e a última respiração, os anos biográficos não são comensuráveis. Setenta anos de vida não podem ser comparados a duas vezes 35 anos do calendário. Graças à sua posição única, cada hora no decorrer do dia, cada dia no decorrer da semana adquirem um valor específico próprio.

Na prática cronológica da vida cotidiana, procedemos com uma notável inconsistência. Prescindimos, ou melhor, jamais atingimos o conceito de um contínuo temporal unidimensional e homogêneo. Na medida em que damos muito crédito às informações dos sentidos, ficamos presos a uma atitude quase pré-copernicana. Preocupado com o ir, com o vir e com o retorno das estações, conhecedor dos movimentos cíclicos do sol, da lua e das estrelas, atento aos alternantes períodos das necessidades pessoais e sua satisfação, o homem concebeu as unidades temporais dos anos, meses e dias. Ele não hesitou em incluir, na unidade do dia, fases tão diferentes como o dia ou a noite, ou tão mutuamente exclusivas como o amanhecer e o anoitecer. Os dias são tratados como unidades separadas, corretamente representados em cada diferente página de um calendário.

mento cronométrico). Dado que, durante o procedimento de medição real, a situação fica aberta em direção ao futuro, o valor definitivo de “t” só pode ser estabelecido de forma retrospectiva. É provavelmente mais correto dizer que a [medida da] distância total foi conceitualizada e desvinculada de qualquer evento real. Se não, começo e fim não poderiam ser unificados numa visão única e ainda ser separados, na relação mais cedo - mais tarde. E a seqüência de segundos, um após o outro, cada um excluindo o outro, não poderia ser reunida num único valor numérico. A isso deve-se acrescentar o postulado de que a quantidade dos 10 segundos medidos hoje é igual à de 10 segundos medidos ontem ou amanhã. No ato de medir o tempo, o homem vai além do tempo medido. É necessário que a capacidade humana combine dois eventos como simultâneos e, ainda assim, distinga um do outro. Além disso, é necessário inverter a direção da seta do tempo e voltar do fim em direção ao começo. O tempo vivido e experienciado não pode ser reduzido à ordem linear do tempo físico. A simultaneidade experimentada precede o problema da simultaneidade que interessa ao físico. 
Ao soar dos sinos, pouco antes do Ano Novo, o ano velho acaba e o ano novo começa de repente. Meia-noite designa a ruptura, o momento em que certos contratos legais terminam e outros começam a ter validade, embora haja contratos que continuem válidos de um ano para outro. Em certas ocasiões, os dias, meses e anos são considerados contínuos, em outras são considerados descontínuos. Oficialmente, a meia-noite marca o começo de um novo dia. Na prática, o dia velho termina com o cair da noite e o novo começa com o amanhecer. O sono interrompe a continuidade da experiência temporal. Pela manhã, retomando o fio dos eventos ali onde, na véspera, o tínhamos deixado, descobrimos a constância da terra e do firmamento, fundamento imutável do fluxo do tempo. Os movimentos cíclicos permitem estabelecer um ponto de retorno que designa fim e começo, permitindonos, então, contar as revoluções [cósmicas]. No entanto, enquanto os ponteiros de um relógio percorrem a circunferência completa, voltando no final ao ponto de partida, o dia de hoje não volta ao seu início. Por isso, a "roda girando" foi um símbolo bem escolhido para a passagem do tempo, tal como ele é experienciado no dia-a-dia.

Todas essas inconsistências, no entanto, não significam um erro. Elas expressam bem a situação do homem que, vivendo no tempo, é capaz de alcançar o além do instante, tanto no futuro quanto no passado e, dessa maneira, estabelecer sua própria posição no vasto horizonte temporal do "não-ainda" e do "não-mais". O mostrador do relógio totalmente parado apresenta, para uma observação simultânea, as vinte e quatro (24) horas do dia, como possibilidades. Já o ponteiro em movimento designa o instante real.

Quando esta conferência começou, às 14:00h, 14 horas deste dia haviam se passado e dez horas ainda estavam por vir. Quando chegar ao seu fim, este dia pertencerá ao passado. A palavra "hoje” usada por todos nós, em inúmeras ocasiões, designa um todo que transcende qualquer experiência imediata. Com uma ingenuidade pragmática e com um bem-sucedido senso prático, localizamos cada hora no conjunto do dia e da mesma forma o dia, dentro da semana, a semana no mês, o mês no ano. Calculamos as horas e as tratamos como se fossem coisas palpáveis. O serviços são pagos por horas de trabalho, ou mesmo por meias-horas, embora cada meia-hora ocorra em um todo que ainda não existe ou que já não mais existe. Se perguntamos ou respondemos à pergunta “quantas horas são?”, descemos da totalidade do dia para a hora, da hora para os minutos, e destes para os segundos. A essa descida se segue uma subida, onde nós (eu) localizamos o momento real de nosso (meu) devir, no horizonte abrangente do tempo do mundo, comum a todos nós. A pergunta "que horas são?" só vale para o momento real da pergunta - o agora. Inseparável daquele que fala, "agora” significa esse verdadeiro instante, no desenvolvimento de seu devir pessoal. Com a pergunta "quantas horas são?”, nós ordenamos nosso devir pessoal na ordem que tudo abrange, no tempo 
do mundo. A resposta "são 14:30h" significa 14:30h para todos nós. Todos os relógios particulares nesta sala, por conseguinte, indicam essa mesma hora.

Quando assinamos um documento importante, ajuntamos a data: 14:30h do dia 19 de janeiro de 1966. Graças ao esquema rotativo do relógio e do calendário, o tempo, a hora, o dia e o mês vão reaparecer, a cada ano. Só o número do ano apresenta uma exceção. A era se estende, aberta em seu final, a partir de um único começo: a fundação da cidade, a primeira Olimpíada, a criação do mundo, o nascimento de Cristo. Assim, existem dois esquemas cronológicos e, correspondentes a eles, duas ordens: uma das tarefas rotineiras do dia-a-dia, outra das decisões irrevogáveis, ambas com um sentido totalmente diferente, no tempo existencial.

Durante nosso tempo de vida, alguma coisa pode, deve ou vai acontecer pela primeira vez. Essa coisa poderá se repetir mais tarde ou talvez não. Com começo e fim, entram em jogo os números ordinais. Eles retiram os instantes individuais de seu anonimato, de modo que esses possam ser determinados, dentro de uma totalidade sistemática ordenada.

Num jogo de basquete, cada quarto [tempo do jogo] tem sua posição característica e seu valor de posição. A tática dos jogadores vai mudando, de acordo com o resultado, do início até o apito final. Perto do final, os times que estão ganhando usam as táticas de "fazer cera". Parafraseando Heidegger, dir-se-ia que eles correm em direção a um fim já antecipado; eles jogam no compasso de uma contagem regressiva, com a intenção de fechar todas as possibilidades abertas. Durante um jogo, a situação permanece aberta para o futuro, pois a decisão (literalmente, o corte final) ainda não foi alcançada. Mas logo o “ainda não” será substituído por um “não-mais”. Quando o jogo termina, até o mais apaixonado torcedor da equipe perdedora deve se resignar e aceitar a derrota como um fait accompli. Retrospectivamente, os torcedores podem estar satisfeitos ou desapontados, felizes ou infelizes, mas não podem mais ter esperança na vitória ou temer a derrota. Humores e emoções têm seu tempo oportuno, sua posição particular entre o começo e o fim, na visão prospectiva ou retrospectiva, dentro de um horizonte temporal.

Embora começo e fim ocorram no tempo, eles não são termos puramente temporais. Eles não permitem uma estrita formalização matemática, porque começo e fim são co-determinados pelo respectivo conteúdo. Alguma coisa "começa”, "termina” ou - se pudermos acrescentar - permanece ou se mantém entre o começo e o fim. O primeiro passo, o primeiro movimento, a primeira palavra são seguidos pelo segundo ou terceiro passos, segundo ou terceiro movimentos e palavras que, por sua vez, determinam a posição do primeiro como primeiro. A sucessão de partes coerentes levam de um começo a um fim. Somente quando tal coerência entre as partes vai se delineando é que, de fato, falamos de começo e fim. O começo acontece, pois, numa dupla oposição: ele se contrapõe aos [momentos] que o antecederam, bem como a um dado conteúdo. O acorde que abre uma sinfonia 
interrompe o barulho que enchia a sala de concertos e introduz algo novo, numa seqüência ordenada e significativa de sons, como numa operação cirúrgica, que dura várias horas e requer, desde o primeiro corte até a última sutura, a aplicação correta dos instrumentos adequados, no lugar e no tempo apropriados. Já que tais tarefas estão inseridas num nível mais alto de ordenamento, superior à indiferença cotidiana de barulhos acidentais ou barulhos arbitrários de ferramentas, elas estão constantemente ameaçadas de possíveis falhas ou deficiências. Uma performance correta requer condições ideais. Somente uma seqüência adequada vai aí ter êxito.

Se bem que a estrutura temporal de tais produções humanas de alto nível coincide, em muitos aspectos, com o desenvolvimento de coisas que têm um começo e um fim naturais, uma correspondência entre elas não é de modo algum completa. Em primeiro lugar, nas produções humanas se executa um plano anteriormente concebido, mediante atividades humanas executadas a partir do plano. Os organismos vivos, entretanto, são sistemas que se auto-sustentam. Em segundo lugar, no caso de produções humanas, o começo coincide, em regra, com a passagem de um nível mais baixo de atividades para níveis de ordem mais alta. No entanto, na vida dos organismos, o começo significa tanto a continuidade da cadeia de gerações quanto a quebra dessa continuidade. Todos nós somos descendentes, saídos de uma longa linha de ancestrais, que chega à mais remota antiguidade. Mas é pelo fato de nos emanciparmos do contínuo das gerações, no drama do nascimento, que finalmente ganhamos nosso status como indivíduos independentes.

Em terceiro lugar, uma operação cirúrgica termina quando a primeira incisão é fechada pela última sutura. Numa sinfonia, o último acorde, último em relação ao compasso de abertura, fecha e, por isso mesmo, completa a obra que agora existe como um todo integrado. Com o último ponto, a costureira completa sua obra, mas com o último suspiro a vida não alcança essa completude, ela apenas chega a seu fim. Na vida das plantas, dos animais e do homem, começo e fim não estão ordenados simetricamente. O começo se liga a seus antecedentes, mas o fim é fechamento definitivo. O começo não é algo absoluto, não é uma creatio ex nihilo, mas a morte, no plano biológico, é uma dissolução no nada; "o resto é silêncio", mesmo quando alguém deixa atrás de si família, propriedades e fama. No berço de um bebê sadio, a morte parece muito longínqua. Mas algum dia, mais tarde, o recém-nascido também sucumbirá e morrerá, como todo mundo. A morte, fim factual da vida, é sua negação final e radical. Mas esse negativo está presente em cada instante real. Ele é uma sombra que a própria vida projeta.

Todos os seres vivos sustentam uma relação especial com seu ambiente, no sentido mais amplo do termo. Eles o co-determinam, dependem dele e, apesar disso, se opõem a ele. Eles se mantêm, ao se opor ao seu ambiente, em todas as interações com ele. Nessa relação, as circunstâncias podem ser favoráveis ou desfavoráveis. Uma geada noturna e tardia, na primavera, pode matar os botões das 


\section{CLÁSSICO S DA \\ PSICO PATOLOGIA}

cerejas; pode chover demais ou muito pouco; a chuva pode chegar cedo demais ou tarde demais, no tempo certo ou fora do tempo.

Durante todos os anos de crescimento, maturidade e declínio, o organismo absorve material de seu meio ambiente, mas deve também transformá-lo, torná-lo parte de si mesmo. A preservação de si nunca é a preservação do status quo. Um organismo só permanecerá vivo na medida em que for capaz de tirar proveito de seu ambiente, num processo contínuo de assimilação e desassimilação. Subsistir, manter-se vivo, significa afirmar-se ante a constante ameaça de deterioração. Significa manter uma baixa entropia, durante toda a vida. Mas não podemos prescindir das forças que nos ameaçam de destruição. Elas são os antagonistas e, como tais, co-atores necessários no drama da vida. Poderíamos dizer, com Burke, que nossos antagonistas são nossos ajudantes.

Sensibilizada por sua experiência pessoal, a paciente cronofóbica descobriu a ambigüidade inerente ao tempo vivido - nesse contexto, depende do indivíduo interpretar uma situação como crescimento e realização, ou como destruição e decadência.

\section{Referências}

Von Gebsattel, E. (1928). Zeitbezogenes Zwangsdenken in der Melancholie. Nervenartz I (3): 274-287. Reeditado in Prolegomena einer Medizinischen Anthropologie. Springer-Verlag: Berlin-Goettingen-Heidelberg, 1954.

Hodge, A. Introduction to Balzac, H.: La peau de chagrin. (The Fatal Skin). C. Paul, Transl. Novel Library: London, 1949.

Wyschogrod, M. Heidegger's ontology and human existence. Dis. Nerv. Syst. (Suppl) 22(4): 50-56, 1961. 